\title{
Monitoring asthma in childhood: management-related issues
}

\author{
Bart L. Rottier ${ }^{1}$, Ernst Eber ${ }^{2}$, Gunilla Hedlin $^{3,4}$, Steve Turner ${ }^{5}$, Edwina Wooler ${ }^{6}$, \\ Eva Mantzourani ${ }^{7}$ and Neeta Kulkarni ${ }^{8}$ on behalf of the ERS Task Force \\ Monitoring Asthma in Children ${ }^{9}$
}

\begin{abstract}
Affiliations: ${ }^{1}$ Dept of Pediatric Pulmonology and Allergology, GRIAC Research Institute, University Medical Center Groningen, University of Groningen, Groningen, The Netherlands. ${ }^{2}$ Respiratory and Allergic Disease Division, Dept of Paediatrics and Adolescence Medicine, Medical University of Graz, Graz, Austria. ${ }^{3}$ Dept of Women's and Children's Health and Centre for Allergy Research, Karolinska Institutet, Stockholm, Sweden. ${ }^{4}$ Astrid Lindgren Children's Hospital, Stockholm, Sweden. ${ }^{5}$ Dept of Paediatrics, University of Aberdeen, Aberdeen, UK. ${ }^{6}$ Royal Alexandra Children's Hospital, Brighton, UK. ${ }^{7}$ Dept of Paediatrics, University Hospital of Heraklion, University of Crete, Heraklion, Greece. ${ }^{8}$ Leicestershire Partnership Trust and Dept of Infection, Immunity and Inflammation, University of Leicester, Leicester, UK. ${ }^{9} \mathrm{~A}$ full list of the ERS Task Force Monitoring Asthma in Children members and their affiliations can be found in the acknowledgements section.
\end{abstract}

Correspondence: Bart L. Rottier, Dept of Pediatric Pulmonology and Allergology, GRIAC Research Institute, University Medical Center Groningen, University of Groningen, PO Box 30001, 9700 RB Groningen, The Netherlands. E-mail: b.l.rottieraumcg.nl

ABSTRACT Management-related issues are an important aspect of monitoring asthma in children in clinical practice. This review summarises the literature on practical aspects of monitoring including adherence to treatment, inhalation technique, ongoing exposure to allergens and irritants, comorbid conditions and side-effects of treatment, as agreed by the European Respiratory Society Task Force on Monitoring Asthma in Childhood.

The evidence indicates that it is important to discuss adherence to treatment in a non-confrontational way at every clinic visit, and take into account a patient's illness and medication beliefs. All task force members teach inhalation techniques at least twice when introducing a new inhalation device and then at least annually. Exposure to second-hand tobacco smoke, combustion-derived air pollutants, house dust mites, fungal spores, pollens and pet dander deserve regular attention during follow-up according to most task force members. In addition, allergic rhinitis should be considered as a cause for poor asthma control. Task force members do not screen for gastro-oesophageal reflux and food allergy. Height and weight are generally measured at least annually to identify individuals who are susceptible to adrenal suppression and to calculate body mass index, even though causality between obesity and asthma has not been established.

In cases of poor asthma control, before stepping up treatment the above aspects of monitoring deserve closer attention.

@ERSpublications

ERS review summarising and discussing the management-related issues regarding the monitoring of asthma in childhood http://ow.ly/JfjGs

This is a supporting document of the ERS Task Force Monitoring Asthma in Children published in the European Respiratory Journal: Pijnenburg MW, Baraldi E, Brand PLP, et al. Monitoring asthma in children. Eur Respir J 2015; 45: 906-925.

Received: May 142014 | Accepted after revision: July 092014

Conflict of interest: Disclosures can be found alongside the online version of this article at err.ersjournals.com

Provenance: Submitted article, peer reviewed.

Copyright CERS 2015. ERR articles are open access and distributed under the terms of the Creative Commons Attribution Non-Commercial Licence 4.0. 


\section{Introduction}

Monitoring is essential to reach the ultimate goal of asthma treatment: obtaining clinical control and reducing future risks to a child with asthma.

Recently, a European Respiratory Society Task Force on Monitoring Asthma in Childhood was published [1]. In the present review we aim to discuss aspects of monitoring related to the management of children with asthma in more detail. Monitoring adherence to treatment, inhalation technique and side-effects of management are issues that should be routinely checked. In the case of poorly controlled asthma other factors might be considered, such as persistent exposure to tobacco smoke or allergens. This review also covers conditions that may aggravate asthma (e.g. allergic rhinitis, environmental irritant exposure and obesity) or that may become apparent during follow-up. Three other articles in this issue of the European Respiratory Review will address general considerations on monitoring asthma in children, monitoring symptoms, exacerbations and quality of life, and monitoring lung function, bronchial responsiveness and inflammation [2-4]. As no formal grading of the evidence was conducted, this statement does not contain recommendations for clinical practice.

\section{Adherence to treatment}

According to the World Health Organization, adherence to treatment is defined as the extent to which a person's behaviour (taking medication, following a diet and/or executing lifestyle changes) corresponds with agreed recommendations from a healthcare provider. Although concordance has more recently been used to express the collaborative relationship between care takers and care providers on the basis of equality, adherence is more commonly used and is, therefore, used in this review.

Poor adherence to medication is common in chronic conditions, and patients' and parents' illness and medication beliefs are by far the most consistent and strongest predictors of adherence to inhaled corticosteroids (ICS), the mainstay of treatment for children with persistent asthma [5-8].

Scheduled close follow-up of children with asthma, providing repeated tailored education, agreement on treatment goals and methods, and addressing patients' and parents' beliefs and concerns, helps to improve asthma control $[6,9,10]$. As adherence to ICS is strongly associated with asthma control, improving adherence, compared to any improvement in specific medical treatment, may be the most cost-effective way to improve asthma control $[11,12]$. In children with problematic asthma, medication issues and issues on prevention of exposures contributed to poor asthma control in nearly half of the children [13].

Taken together, the evidence indicates that adherence to maintenance treatment is a matter that warrants attention at each appointment with a healthcare provider, in particular in children with poorly controlled asthma.

\section{How to measure adherence}

There is no gold standard to measure adherence to treatment. Interviews and self-reporting by patients and/or parents tend to overestimate adherence. Face-to-face interviews have been demonstrated to be more effective than computer-assisted or written interviews in reporting adherence, but still overestimates adherence to treatment [14]. Pharmacy refill rates seem to be as equally unreliable as self-reported adherence [15]. Electronic data recording may be the most reliable way to assess adherence, however, this should be balanced against extra costs [14]. In a recent study in 2-6-year-old children, electronically recorded adherence demonstrated a relatively high median adherence rate of $92 \%$ (interquartile range 76-97\%) over a 3-month period [16]. Importantly, parents who believed that ICS maintenance therapy was needed for their child's health, those who viewed ICS administration as convenient and those who expected little harm from medication had higher adherence rates to ICS. This evidence suggests that all these are important issues for follow-up visits of children with asthma.

In clinical trials where electronic monitoring was applied, adherence was $\sim 70 \%$ for all diseases that needed twice daily dosing of medication [17].

In general, an increasing number of daily doses leads to decreased adherence, even in clinical trials, although the effect is small [17]. In real life, adherence can therefore often be expected to be lower. Additional risk factors for poor adherence are growing up in single parent families, replacement of the caregiver, lower education of the mother and prescribing more than two inhalations a day [18, 19]. In most studies a link between education level and adherence was not shown.

Motivational interviewing is a patient-centred approach to discuss behaviour change by helping children or their parents to say why and how they might change [20]. A systematic review that included 72 studies (no paediatric studies) found that motivational interviewing outperformed traditional advice given in $80 \%$ of studies [21]. The evidence suggests that adherence can be improved by applying specific communicative consultation skills [22]. 
All task force members discuss adherence to treatment at every patient visit and a non-confrontational way of interviewing may be preferred, which may be sufficient in children with mild-to-moderate disease. However, in children with severe, uncontrolled asthma, assessing adherence by electronic measurement or directly observed therapies is more reliable and might be considered. If these are unavailable, prescription records or refill rates could provide useful information. In some cases home visits may be useful. Educational interventions alone are insufficient to enhance medication adherence in children and adolescents [23].

\section{Inhaler technique}

After adequate adherence to treatment, correct inhaler technique is a prerequisite of successful asthma treatment. Correct inhaler technique involves using an age appropriate device, handling the device correctly and performing an (age dependent) adequate breathing manoeuvre [24]. Healthcare professionals should demonstrate any asthma inhaler device that a child needs to use to the child and their family and then have the child or parent demonstrate how they would use the device [25]. Less than one-third of asthmatic children receiving treatment with a dry powder inhaler performed all essential steps correctly compared with $67 \%$ of children using a pressurised metered dose inhaler (pMDI)/spacer combination [26]. Repeated instruction led to improved performance compared to a single instruction given by a general practitioner [26].

In younger children it may be necessary to demonstrate to the parents how to hold a child securely to aid treatment administration, particularly with a spacer and facemask. Furthermore, patients should be actively encouraged to ask questions regarding asthma medication devices [25]. In adults, there is evidence that a patient is more likely to correctly use an inhaler that they like [27]. Although in general it is logical to provide both anti-inflammatory and rescue medication in one type of inhaler, concurrent use of pMDIs and dry powder inhalers (DPIs) by children did not adversely affect spacer/inhalation technique in an observational study [28].

It has been well documented that children learn through play and utilising some simple play strategies can improve inhaler technique. Placing stickers on spacers, distracting children with nursery rhymes or videos and trying to make the whole experience fun rather than a stressful intervention can help with the acceptance of inhaler devices. Although appealing, this is not supported by strong evidence; for example, an attractive spacer device like the "funhaler" did not improve adherence or asthma control $[29,30]$.

In order to achieve and maintain a correct inhalation technique, the procedure has to be taught and checked and taught again; the number of newly referred patients demonstrating a correct inhalation technique improved from 57.4 to $97.9 \%$ after three comprehensive instruction sessions [31]. Telepharmacy counselling via interactive compressed video (which allows real-time video and audio interaction between individuals in different physical locations) was superior to education provided via written instructions on an inhaler package insert in adolescents with asthma [32]. Instruction of inhaler technique by telephone resulted in an improvement in inhaler technique both for pMDIs and for DPIs in adults [33]. Also, repeated instruction by a respiratory therapist led to a relevant improvement in inhaler technique [34].

Although it might be anticipated that combination inhalers improve adherence compared with the use of separate inhalers, this was not demonstrated in a randomised controlled trial [35].

The evidence indicates that inhaler technique is improved if taught, repeated back and checked at least twice when new drugs or devices are prescribed, with deteriorating asthma control or at least annually. The European Respiratory Society/International Society for Aerosols in Medicine consensus paper provides detailed recommendations on checking inhalation technique and states that this should be performed regularly and that adherence should be reviewed at every visit. Furthermore, this paper recommends not switching to a new device without the patient's involvement or without follow-up education on how to use the device properly [24].

\section{Side-effects of drug treatment}

During long-term use of low-to-moderate doses of ICS (beclometasone $200-400 \mu \mathrm{g} \cdot \mathrm{day}^{-1}$ or equivalent), the risk of systemic side-effects is very low $[36,37]$. Height growth may be reduced by approximately 0.5-2 cm during the first 1-2 years of treatment [38]; whether or not this persists over time a matter of debate $[39,40]$. Even if the effect is persistent, the advantages of ICS maintenance therapy outweigh its risks [37]. Although more serious systemic side-effects, such as adrenal suppression, are almost exclusively seen during treatment with high-dose ICS, they may occur in children on low-dose ICS [41]. Children using high doses of ICS warrant monitoring for possible adrenal suppression. More research is needed to define which adrenal suppression tests are useful and in which children. Most members of the task force would consider nasal and topical corticosteroids when assessing total corticosteroid dose. 
Local side-effects, such as thrush and hoarseness, are rare and easily manageable by teeth brushing or mouth rinsing after administration of ICS [42]. Apart from monitoring height growth, which is mandatory for all paediatric chronic conditions, there is no need to monitor children with asthma with respect to potential side-effects of ICS maintenance therapy. Height and weight should be measured at least annually but preferably at every routine visit [43]. It may be important to discuss the fear of side-effects with parents during the clinic visits.

\section{Monitoring diseases that may aggravate asthma}

Food allergy, obesity and gastro-oesophageal reflux are conditions that may present simultaneously with asthma, may aggravate asthma or may mimic asthma. Their potential role has recently been reviewed and therefore is only discussed briefly here [44]. It may be necessary to identify these comorbidities and treat them accordingly, particularly in those with poor asthma control.

Asthmatic children with rhinitis, compared with those without, have been reported to have poorer asthma control, reduced quality of life, increased risk for emergency visits or hospitalisations and higher healthcare costs [45-48]. Signs and symptoms suggestive of rhinitis and rhinosinusitis are described in table 1. Most physicians ask about these symptoms and look for them at least annually. Although treatment for rhinitis has not been proven to improve asthma control, it is considered good practice to ensure that rhinitis symptoms are managed appropriately in a child with asthma.

Food allergy is commonly considered to be a risk factor for poor asthma control based on its association with severe and even fatal asthma exacerbations $[49,50]$. However, it should be realised that the diagnosis of food allergy was not based on the gold standard for food allergy, the double-blind, placebo-controlled food challenge, in any of these studies. As up to $80 \%$ of children sensitised to a certain food do not show clinical allergy following oral ingestion of the food [51, 52], most studies assessed sensitisation for foods and not allergy as a risk factor. Most patients with sensitisation to foods are also sensitised to aeroallergens, which is associated with a distinct, clinically more severe, atopic phenotype [53]. Therefore, it is not the food allergy per se but sensitisation to multiple foods and aeroallergens that may be a risk factor for poor asthma control or severe exacerbations. In children with asthma, without any history of adverse reactions to foods, the members of the task force do not screen for food allergy. Children with asthma with confirmed food allergy and anaphylaxis might receive an adrenalin auto injector after appropriate training in its use [54].

Gastro-oesophageal reflux can trigger cough in children, whether they are asthmatic or not $[55,56]$. Based on largely descriptive small studies, gastro-oesophageal reflux has been suggested to cause impaired asthma control in children but there is limited data to support this. Usually these studies do not include an adequate control group and a causal link between gastro-oesophageal reflux and asthma symptoms

\section{TABLE 1 Symptoms and signs of rhinitis/rhinosinusitis}

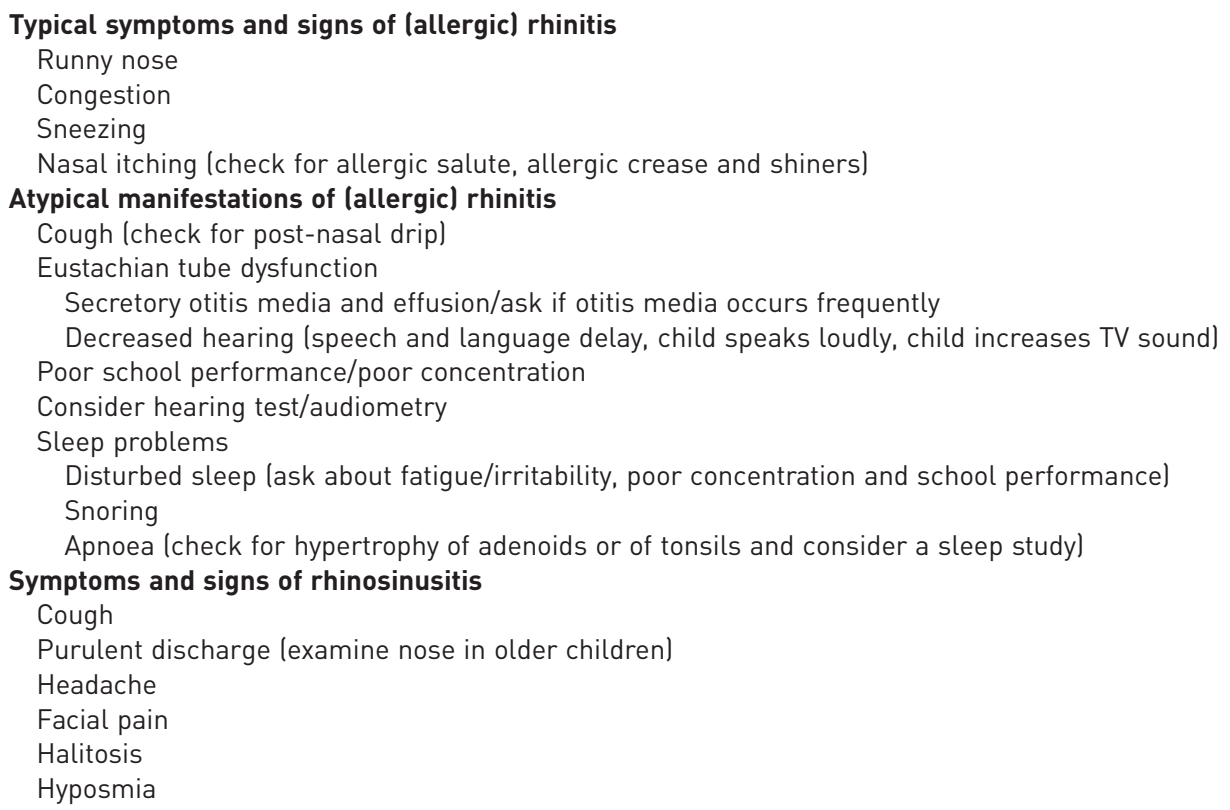


could not be proven. The results from two controlled studies do not support wide-spread use of oesophageal $\mathrm{pH}$ testing in children with asthma who have symptoms despite being on controller medication [57, 58]. Treatment with lansoprazole in children with poorly controlled asthma, without symptoms of gastro-oesophageal reflux, did not improve symptoms or lung function. Therefore, diagnostic testing for gastro-oesophageal reflux has no role in monitoring asthma in children.

The relationship between obesity and asthma is complex and not yet fully understood. Being overweight per se is known to induce respiratory symptoms such as dyspnoea and wheezing which can mimic asthma $[59,60]$. Furthermore, obesity can have metabolic effects that contribute to airway inflammation [61, 62]. Comorbidity, including gastro-oesophageal reflux and obstructive sleep apnoea, may present symptoms that mimic asthma. More studies are needed to establish whether poorly controlled asthma leads to a more sedentary lifestyle and increasing obesity or whether obesity in itself decreases asthma control and, if so, whether it is just symptoms or also objective measures of control [63]. In obese patients with uncontrolled asthma it is probably not sufficient to rely on symptoms alone. Exercise testing and/or measurement of markers of airway inflammation may be useful. Therefore, the task force members monitor weight and height in children with asthma in order to record body mass index.

\section{Environmental factors}

Multiple environmental agents are known to worsen asthma symptoms; in this section only the most common indoor and outdoor environmental factors will be discussed, such as tobacco smoke, combustion-derived air pollutants, house dust mites, fungal spores, pollens and pet dander.

\section{Tobacco smoke}

There is good evidence that second-hand tobacco smoke exposure causes asthma, more severe asthma symptoms, bronchial hyperresponsiveness, airways inflammation and adverse effects on respiratory health in children and adolescents [64-67]. Studies in emergency departments have identified that children presenting with wheeze are more likely to be exposed to second-hand tobacco smoke compared with those presenting with other conditions and that second-hand tobacco smoke exposure is weakly associated with more severe acute asthma $[66,68]$. Due to ethical considerations, no study has deliberately exposed children to second-hand tobacco smoke in a randomised controlled trial, but intervention studies have sought to reduce second-hand tobacco smoke exposure in children with asthma with mixed success. In a study where asthma education included awareness of second-hand tobacco smoke exposure, exposure was reduced in only $17 \%$ of households but children living in these households experienced a $50 \%$ decrease in the number of hospital admissions over the following year [69]. A second study in children with asthma, of whom 50\% were exposed to second-hand tobacco smoke, aimed at reducing second-hand tobacco smoke exposure by educating the parents, in combination with a high efficiency particulate air filter in the child's bedroom and allergen reduction interventions [70]. Children who received the intervention had reduced symptoms and exacerbations during the 1-year trial plus the subsequent year but the intervention was not associated with a reduction in the number of households with smokers. A third study recruited young children with asthma whose parents smoked and studied an educational intervention, which included feedback on the child's urinary cotinine; the intervention was associated with reduced exacerbations but a nonsignificant reduction in urinary cotinine [71]. A better understanding of how to motivate parents of children with asthma to change their smoking habits is required and once this has been achieved the impact of such an intervention on asthma exacerbations and control should be evaluated $[72,73]$.

Self-reported exposure to second-hand tobacco smoke by parents and older children is generally unreliable [74]. There are several methods (measurements of cotinine, hair or nail nicotine, exhaled carbon monoxide and airborne nicotine) to objectively measure children's exposure to second-hand tobacco smoke but no gold standard. Currently there is no single recommended method for monitoring second-hand tobacco smoke exposure in children with asthma.

\section{Air pollution}

Outdoor air pollution is a mixture of multiple toxic chemicals and gases, with varying composition depending on the source and meteorological conditions. Children appear to be more vulnerable to health effects of air pollution than adults due to a higher minute ventilation, higher levels of physical activity outdoors and that fact that their lungs are still developing [75-78]. A recent review, which included 20 studies in children investigating evidence of air pollution causing exacerbations of respiratory symptoms, found a high consistency of positive association [79]. This conclusion was similar to an earlier extensive review conducted by the World Health Organization [80]. In a more recent study of 40 children living near roads, SpIRA-Cohen et al. [81] showed that the relative risk for shortness of breath, wheeze and total symptoms was associated with personal elemental carbon exposure. In Greece, mean daily concentrations 
of particles with a 50\% cut-off aerodynamic diameter of $10 \mu \mathrm{m}$ were significantly related to asthma admissions over a 4-year period in 3600 children [82].

There is also a positive association between exposure to traffic-related air pollution and reduced growth in lung function [83]. The measurement of outdoor pollutants is mainly carried out for regulatory purposes and is currently not used in clinical settings to monitor children with asthma.

The most common source of indoor pollutants is incomplete combustion of biomass and solid fuels (e.g. dung, wood, agricultural residues, charcoal and coal) [84], kerosene, candles and incense [85, 86], and mosquito coils [87]. Exposure to mosquito coil smoke is common among working class populations in warm climates [88]. Chronic exposure is associated with bronchial irritation, increased sputum production and persistent wheeze in children [88-90]. A recent study from Taiwan, in which 3764 school children (mean age 12 years) were evaluated, demonstrated that the frequency of incense burning at home was associated with an increased risk of current asthma, medication use and exercise-induced wheeze [87]. Indoor dampness is another important factor that is associated with a higher risk of asthma [91, 92].

\section{Environmental allergen load}

Common aeroallergens include house dust mites, pollens, pet allergens and fungal spores. In a recent review it was concluded that chemical and physical measures aimed at reducing house dust mite exposure could not be recommended; however, the meta-analysis was considered flawed for various reasons [93, 94]. In a large study of 937 inner city children with asthma, individualised environmental intervention programmes reduced exposure to indoor allergens and resulted in decreased asthma morbidity [70].

Most task force members ask specific questions, tailored to the local environment, about exposures likely to increase the risk of asthma or to trigger asthma exacerbations and these questions should be included in the assessment of all asthmatic children (table 2). Regional pollen counts are freely available on TV or the internet, and these may guide patients and parents in strategies to manage a potential increase in symptoms. Environmental manipulation within the home should be multifaceted, and may incur the family a great deal of time and expense with the possibility that the benefits may be limited. Most task force members do not take single measures to reduce allergen load as they are likely to be of little benefit.

The evidence for routine home visits to children with asthma to assess the environmental allergen load is limited, but such visits may be part of the work-up of children with persistent severe asthma before any changes or increase in treatment regimens are considered [95].

\section{Socioeconomic circumstances}

Low education of parents is associated with under treatment of children with asthma and risk of exacerbations [7]. Socially disadvantaged children with asthma have elevated asthma morbidity including more emergency room visits. Less access to quality healthcare and medications, more environmental exposures (including allergens, pollution and environmental tobacco smoke), psychosocial stress, exposure to violence and belonging to a minority group may all account for this [96]. It may be speculated that improving social and educational factors may improve asthma management in these children.

\section{Conclusion}

Monitoring of asthma in children includes an evaluation of adherence on every check-up. Current practice by task force members is to teach inhalation technique at least twice when new drugs or devices are prescribed, and then at least annually or with deteriorating asthma control.

TABLE 2 Possible pollutants/exposures for discussion with parents and children in the clinic/ during a home visit

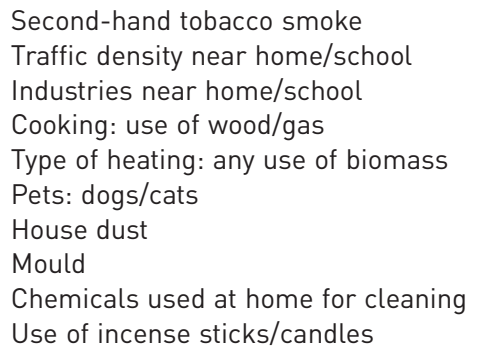


Apart from the generally accepted monitoring of height gain, there is no need to monitor children with asthma with respect to potential side-effects of ICS therapy. Particularly in children with poor asthma control, it is practice to screen for allergic or nonallergic rhinitis/rhinosinusitis and treat accordingly.

There is no evidence to use oesophageal $\mathrm{pH}$ testing in asthmatic children who have symptoms despite use of controller medication. Task force members do not screen for food allergy, except in children with a history suggesting food allergy and asthma.

All task force members educate parents about the possible environmental agents (e.g. second-hand tobacco smoke, other air pollutants) triggering asthma exacerbations. Single measures to reduce allergen loads are likely to be of little benefit.

\section{Acknowledgements}

The Task Force members and their affiliations are as follows. Bart L. Rottier: Dept of Pediatric Pulmonology and Allergology, GRIAC Research Institute, University Medical Center Groningen, University of Groningen, Groningen, The Netherlands; Ernst Eber: Respiratory and Allergic Disease Division, Dept of Paediatrics and Adolescence Medicine, Medical University of Graz, Graz, Austria; Gunilla Hedlin: Dept of Women's and Children's Health and Centre for Allergy Research, Karolinska Institutet, and Astrid Lindgren Children's Hospital, Stockholm, Sweden; Steve Turner: Dept of Paediatrics, University of Aberdeen, Aberdeen, UK; Edwina Wooler: Royal Alexandra Children's Hospital, Brighton, UK; Eva Mantzourani: Dept of Paediatrics, University Hospital of Heraklion, University of Crete, Heraklion, Greece; Neeta Kulkarni: Leicestershire Partnership Trust and Dept of Infection, Immunity and Inflammation, University of Leicester, Leicester, UK; Eugenio Baraldi: Women's and Children's Health Dept, Unit of Respiratory Medicine and Allergy, University of Padova, Padova, Italy; Paul L.P. Brand: Dept of Paediatrics/Princess Amalia Children's Centre, Isala Hospital, Zwolle, and UMCG Postgraduate School of Medicine, University Medical Centre and University of Groningen, Groningen, The Netherlands; Kai-Hakon Carlsen: Dept of Paediatrics, Women and Children's Division, University of Oslo, and Oslo University Hospital, Oslo, Norway; Thomas Frischer: Dept Paediatrics and Paediatric Surgery, Wilhelminenspital, Vienna, Austria; Christiane Lex: Dept of Paediatric Cardiology and Intensive Care Medicine, Division of Pediatric Respiratory Medicine, University Hospital Goettingen, Goettingen, Germany; Karin C. Lødrup Carlsen: Dept of Paediatrics, Women and Children's Division, Oslo University Hospital, and Dept of Paediatrics, Faculty of Medicine, University of Oslo, Oslo, Norway; Mika J. Mäkelä: Skin and Allergy Hospital, Helsinki University Hospital, Helsinki, Finland; Alexander Moeller: Division of Respiratory Medicine, University Children's Hospital Zurich, Zurich, Switzerland; Ian Pavord: Dept of Respiratory Medicine, University of Oxford, Oxford, UK; Giorgio Piacentini: Paediatric Section, Dept of Life and Reproduction Sciences, University of Verona, Verona, Italy; Mariëlle W. Pijnenburg: Dept of Paediatrics/Paediatric Respiratory Medicine, Erasmus MC - Sophia Children's Hospital, Rotterdam, The Netherlands; David Price: Dept of Primary Care Respiratory Medicine, Academic Primary Care, Division of Applied Health Sciences, University of Aberdeen, Aberdeen, UK; Sejal Saglani: Leukocyte Biology and Respiratory Paediatrics, National Heart and Lung Institute, Imperial College London, London, UK; Peter D. Sly: Queensland Children's Medical Research Institute, The University of Queensland, Brisbane, Australia; Stanley J. Szefler: Children's Hospital Colorado and University of Colorado Denver School of Medicine, Denver, CO, USA.

\section{References}

Pijnenburg MW, Baraldi E, Brand PLP, et al. Monitoring asthma in children. Eur Respir J 2015; 45: 906-925.

Lødrup Carlsen KC, Pijnenburg MW. Monitoring asthma in childhood. Eur Respir Rev 2015; 24: 178-186.

Brand PLP, Mäkelä MJ, Szefler SJ, et al. Monitoring asthma in childhood: symptoms, exacerbations and quality of life. Eur Respir Rev 2015; 24: 187-193.

4 Moeller A, Carlsen K-H, Sly PD, et al. Monitoring asthma in childhood: lung function, bronchial responsiveness and inflammation. Eur Respir Rev 2015; 24: 204-215.

5 Kaptein AA, Hughes BM, Scharloo M, et al. Illness perceptions about asthma are determinants of outcome. J Asthma 2008; 45: 459-464.

6 Klok T, Brand PL, Bomhof-Roordink H, et al. Parental illness perceptions and medication perceptions in childhood asthma, a focus group study. Acta Paediatr 2011; 100: 248-252.

7 Koster ES, Wijga AH, Koppelman GH, et al. Uncontrolled asthma at age 8: the importance of parental perception towards medication. Pediatr Allergy Immunol 2011; 22: 462-468.

8 Kaptein AA, Klok T, Moss-Morris R, et al. Illness perceptions: impact on self-management and control in asthma. Curr Opin Allergy Clin Immunol 2010; 10: 194-199.

9 Brouwer AF, Brand PL. Asthma education and monitoring: what has been shown to work. Paediatr Respir Rev 2008; 9: 193-199.

10 Kuethe MC, Vaessen-Verberne AA, Bindels PJ, et al. Children with asthma on inhaled corticosteroids managed in general practice or by hospital paediatricians: is there a difference? Prim Care Respir J 2010; 19: 62-67.

11 Jentzsch NS, Camargos P, Sarinho ES, et al. Adherence rate to beclomethasone dipropionate and the level of asthma control. Respir Med 2012; 106: 338-343.

12 World Health Organization. Adherence to long-term therapies. Evidence for Action. Geneva, WHO, 2003.

13 Bracken M, Fleming L, Hall P, et al. The importance of nurse-led home visits in the assessment of children with problematic asthma. Arch Dis Child 2009; 94: 780-784.

14 Bender BG, Bartlett SJ, Rand CS, et al. Impact of interview mode on accuracy of child and parent report of adherence with asthma-controller medication. Pediatrics 2007; 120: e471-e477.

15 Otsuki M, Eakin MN, Rand CS, et al. Adherence feedback to improve asthma outcomes among inner-city children: a randomized trial. Pediatrics 2009; 124: 1513-1521.

16 Klok T, Kaptein AA, Duiverman EJ, et al. High inhaled corticosteroids adherence in childhood asthma: the role of medication beliefs. Eur Respir J 2012; 40: 1149-1155.

17 Claxton AJ, Cramer J, Pierce C. A systematic review of the associations between dose regimens and medication compliance. Clin Ther 2001; 23: 1296-1310. 
18 Spicher M, Bollers N, Chinn T, et al. Adherence in single-parent households in a long-term asthma clinical trial. Pediatr Nurs 2012; 38: 207-213.

19 Lasmar L, Camargos P, Bousquet J, et al. Factors related to lower adherence rates to inhaled corticosteroids in children and adolescents: a prospective randomized cohort study. J Trop Pediatr 2009; 55: 20-25.

20 Rollnick S, Butler CC, Kinnersley P, et al. Motivational interviewing. BMJ 2010; 340: C1900.

21 Rubak S, Sandbaek A, Lauritzen T, et al. Motivational interviewing: a systematic review and meta-analysis. $B r$ Gen Pract 2005; 55: 305-312.

22 Brand PL, Klok T, Kaptein AA. Using communication skills to improve adherence in children with chronic disease: the adherence equation. Paediatr Respir Rev 2013; 14: 219-223.

23 Dean AJ, Walters J, Hall A. A systematic review of interventions to enhance medication adherence in children and adolescents with chronic illness. Arch Dis Child 2010; 95: 717-723.

24 Laube BL, Janssens HM, de Jongh FH, et al. What the pulmonary specialist should know about the new inhalation therapies. Eur Respir J 2011; 37: 1308-1331.

25 Sleath B, Carpenter DM, Slota C, et al. Communication during pediatric asthma visits and self-reported asthma medication adherence. Pediatrics 2012; 130: 627-633.

26 Kamps AW, van Ewijk B, Roorda RJ, et al. Poor inhalation technique, even after inhalation instructions, in children with asthma. Pediatr Pulmonol 2000; 29: 39-42.

27 Lenney J, Innes JA, Crompton GK. Inappropriate inhaler use: assessment of use and patient preference of seven inhalation devices. EDICI. Respir Med 2000; 94: 496-500.

28 Chan DS, Callahan CW, Hatch-Pigott VB, et al. Concurrent use of metered-dose and dry powder inhalers by children with persistent asthma does not adversely affect spacer/inhaler technique. Ann Pharmacother 2006; 40: 1743-1746.

29 Schultz A, Sly PD, Zhang G, et al. Incentive device improves spacer technique but not clinical outcome in preschool children with asthma. J Paediatr Child Health 2012; 48: 52-56.

30 Burgess SW, Sly PD, Cooper DM, et al. Novel spacer device does not improve adherence in childhood asthma. Pediatr Pulmonol 2007; 42: 736-739.

31 Kamps AW, Brand PL, Roorda RJ. Determinants of correct inhalation technique in children attending a hospital-based asthma clinic. Acta Paediatr 2002; 91: 159-163.

32 Bynum A, Hopkins D, Thomas A, et al. The effect of telepharmacy counseling on metered-dose inhaler technique among adolescents with asthma in rural Arkansas. Telemed J E Health 2001; 7: 207-217.

33 Nelson P, Young HN, Knobloch MJ, et al. Telephonic monitoring and optimization of inhaler technique. Telemed $J$ E Health 2011; 17: 734-740.

34 Minai BA, Martin JE, Cohn RC. Results of a physician and respiratory therapist collaborative effort to improve long-term metered-dose inhaler technique in a pediatric asthma clinic. Respir Care 2004; 49: 600-605.

35 Perrin K, Williams M, Wijesinghe M, et al. Randomized controlled trial of adherence with single or combination inhaled corticosteroid/long-acting beta-agonist inhaler therapy in asthma. J Allergy Clin Immunol 2010; 126: 505-510.

36 Leone FT, Fish JE, Szefler SJ, et al. Systematic review of the evidence regarding potential complications of inhaled corticosteroid use in asthma: collaboration of American College of Chest Physicians, American Academy of Allergy, Asthma, and Immunology, and American College of Allergy, Asthma, and Immunology. Chest 2003; 124: $2329-2340$.

37 Pedersen S. Do the benefits of daily inhaled steroid treatment of mild asthma outweigh the risks? Arch Dis Child 2008; 93: 644-645

38 Pedersen S. Do inhaled corticosteroids inhibit growth in children? Am J Respir Crit Care Med 2001; 164: 521-535.

39 Agertoft L, Pedersen S. Effect of long-term treatment with inhaled budesonide on adult height in children with asthma. N Engl J Med 2000; 343: 1064-1069.

40 Kelly HW, Sternberg AL, Lescher R, et al. Effect of inhaled glucocorticoids in childhood on adult height. $N$ Engl $J$ Med 2012; 367: 904-912.

41 Todd GR, Acerini CL, Ross-Russell R, et al. Survey of adrenal crisis associated with inhaled corticosteroids in the United Kingdom. Arch Dis Child 2002; 87: 457-461.

42 Carlsen KH. Inhaled steroids and local side-effects. Allergy 2001; 56: 925-927.

43 Global Initiative for Asthma. Global Strategy for Asthma Management and Prevention updated 2012. www.ginasthma org/local/uploads/files/GINA_Report_March13_1.pdf Date last updated: 2014. Date last accessed: September 7, 2013.

44 de Groot EP, Duiverman EJ, Brand PL. Comorbidities of asthma during childhood: possibly important, yet poorly studied. Eur Respir J 2010; 36: 671-678.

45 Chawes BL, Bonnelykke K, Kreiner-Moller E, et al. Children with allergic and nonallergic rhinitis have a similar risk of asthma. J Allergy Clin Immunol 2010; 126: 567-573.

46 de Groot EP, Nijkamp A, Duiverman EJ, et al. Allergic rhinitis is associated with poor asthma control in children with asthma. Thorax 2012; 67: 582-587.

47 Kang HY, Park CS, Bang HR, et al. Effect of allergic rhinitis on the use and cost of health services by children with asthma. Yonsei Med J 2008; 49: 521-529.

48 Kiotseridis H, Cilio CM, Bjermer L, et al. Quality of life in children and adolescents with respiratory allergy, assessed with a generic and disease-specific instrument. Clin Respir J 2013; 7: 168-175.

49 Gillman A, Douglass JA. What do asthmatics have to fear from food and additive allergy? Clin Exp Allergy 2010; 40: 1295-1302.

50 Bergstrom SE, Boman G, Eriksson L, et al. Asthma mortality among Swedish children and young adults, a 10-year study. Respir Med 2008; 102: 1335-1341.

51 Chafen JJ, Newberry SJ, Riedl MA, et al. Diagnosing and managing common food allergies: a systematic review. JAMA 2010; 303: 1848-1856.

52 Nicolaou N, Poorafshar M, Murray C, et al. Allergy or tolerance in children sensitized to peanut: prevalence and differentiation using component-resolved diagnostics. J Allergy Clin Immunol 2010; 125: 191-197.

53 de Jong AB, Dikkeschei LD, Brand PL. Sensitization patterns to food and inhalant allergens in childhood: a comparison of non-sensitized, monosensitized, and polysensitized children. Pediatr Allergy Immunol 2011; 22: $166-171$.

54 Muraro A, Werfel T, Hoffmann-Sommergruber K, et al. EAACI food allergy and anaphylaxis guidelines: diagnosis and management of food allergy. Allergy 2014; 69: 1008-1025. 
Blondeau K, Mertens V, Dupont L, et al. The relationship between gastroesophageal reflux and cough in children with chronic unexplained cough using combined impedance-pH-manometry recordings. Pediatr Pulmonol 2011; 46: 286-294. Tolia V, Vandenplas Y. Systematic review: the extra-oesophageal symptoms of gastro-oesophageal reflux disease in children. Aliment Pharmacol Ther 2009; 29: 258-272.

Stordal K, Johannesdottir GB, Bentsen BS, et al. Acid suppression does not change respiratory symptoms in children with asthma and gastro-oesophageal reflux disease. Arch Dis Child 2005; 90: 956-960.

Holbrook JT, Wise RA, Gold BD, et al. Lansoprazole for children with poorly controlled asthma: a randomized controlled trial. JAMA 2012; 307: 373-381.

Corbo GM, Forastiere F, De Sario M, et al. Wheeze and asthma in children - associations with body mass index, sports, television viewing, and diet. Epidemiology 2008; 19: 747-755.

Schachter LM, Peat JK, Salome CM. Asthma and atopy in overweight children. Thorax 2003; 58: 1031-1035.

Cibella F, Cuttitta G, La Grutta S, et al. A cross-sectional study assessing the relationship between BMI, asthma, atopy, and eNO among schoolchildren. Ann Allergy Asthma Immunol 2011; 107: 330-336.

Forno E, Lescher R, Strunk R, et al. Decreased response to inhaled steroids in overweight and obese asthmatic children. J Allergy Clin Immunol 2011; 127: 741-749.

O’Byrne PM, Pedersen S, Schatz M, et al. The poorly explored impact of uncontrolled asthma. Chest 2013; 143: 511-523.

Collins RA, Parsons F, Deverell M, et al. Risk factors for bronchial hyperresponsiveness in teenagers differ with sex and atopic status. J Allergy Clin Immunol 2011; 128: 301-307.

Kabir Z, Manning PJ, Holohan J, et al. Second-hand smoke exposure in cars and respiratory health effects in children. Eur Respir J 2009; 34: 629-633.

Vargas PA, Brenner B, Clark S, et al. Exposure to environmental tobacco smoke among children presenting to the emergency department with acute asthma: a multicenter study. Pediatr Pulmonol 2007; 42: 646-655.

Cook DG, Strachan DP. Summary of effects of parental smoking on the respiratory health of children and implications for research. Thorax 1999; 54: 357-365.

Chang MY, Hogan AD, Rakes GP, et al. Salivary cotinine levels in children presenting with wheezing to an emergency department. Pediatr Pulmonol 2000; 29: 257-263.

Gerald LB, Gerald JK, Gibson L, et al. Changes in environmental tobacco smoke exposure and asthma morbidity among urban school children. Chest 2009; 135: 911-916.

Morgan WJ, Crain EF, Gruchalla RS, et al. Results of a home-based environmental intervention among urban children with asthma. N Engl J Med 2004; 351: 1068-1080.

Wilson SR, Yamada EG, Sudhakar R, et al. A controlled trial of an environmental tobacco smoke reduction intervention in low-income children with asthma. Chest 2001; 120: 1709-1722.

2 Priest N, Roseby R, Waters E, et al. Family and carer smoking control programmes for reducing children's exposure to environmental tobacco smoke. Cochrane Database Syst Rev 2008; 4: CD001746.

Wilson SR, Farber HJ, Knowles SB, et al. A randomized trial of parental behavioral counseling and cotinine feedback for lowering environmental tobacco smoke exposure in children with asthma results of the LET'S manage asthma trial. Chest 2011; 139: 581-590.

4 Galan I, Mayo E, Lopez MJ, et al. Validity of self-reported exposure to second-hand smoke in hospitality venues. Environ Res 2014; 133C: 1-3.

Plopper CG, Fanucchi MV. Do urban environmental pollutants exacerbate childhood lung diseases? Environ Health Perspect 2000; 108: A252-A253.

Pinkerton KE, Joad JP. The mammalian respiratory system and critical windows of exposure for children's health. Environ Health Perspect 2000; 108: Suppl. 3, 457-462.

Kim JJ, Ambient Academy of Pediatrics Committee on Environmental Health. Ambient air pollution: health hazards to children. Pediatrics 2004; 114: 1699-1707.

Dietert RR, Etzel RA, Chen D, et al. Workshop to identify critical windows of exposure for children's health: immune and respiratory systems work group summary. Environ Health Perspect 2000; 108: Suppl. 3, $483-490$.

HEI Panel on the Health Effects of Traffic-Related Air Pollution. Traffic-related air pollution: a critical review of the literature on emissions, exposure, and health effects report. HEI special Report. Boston, Health Effects Institute, 2010.

0 World Health Organization Europe. Effects of Air Pollution on Children's Health and Development. A Review of the Evidence. WHO Regional Office for Europe, Copenhagen, Denmark, 2005. www.euro.who.int/_data/assets/pdf_file/ 0010/74728/E86575.pdf

1 Spira-Cohen A, Chen LC, Kendall M, et al. Personal exposures to traffic-related air pollution and acute respiratory health among Bronx schoolchildren with asthma. Environ Health Perspect 2011; 119: 559-565.

Nastos PT, Paliatsos AG, Anthracopoulos MB, et al. Outdoor particulate matter and childhood asthma admissions in Athens, Greece: a time-series study. Environ Health 2010; 9: 45

Gauderman WJ, Avol E, Gilliland F, et al. The effect of air pollution on lung development from 10 to 18 years of age. N Engl J Med 2004; 351: 1057-1067.

4 Torres-Duque C, Maldonado D, Perez-Padilla R, et al. Biomass fuels and respiratory diseases: a review of the evidence. Proc Am Thorac Soc 2008; 5: 577-590.

Lin TC, Krishnaswamy G, Chi DS. Incense smoke: clinical, structural and molecular effects on airway disease. Clin Mol Allergy 2008; 6: 3.

6 Wang IJ, Tsai CH, Chen $\mathrm{CH}$, et al. Glutathione S-transferase, incense burning and asthma in children. Eur Respir J 2011; 37: 1371-1377.

87 Liu W, Zhang J, Hashim JH, et al. Mosquito coil emissions and health implications. Environ Health Perspect 2003; 111: $1454-1460$.

8 Liu W, Zhang J, Hashim JH, et al. Mosquito coil smoke and respiratory health among Hong Kong Chinese: results of three epidemiological studies. Indoor Built Environ 1994; 3: 304-310.

Azizi BH, Henry RL. The effects of indoor environmental factors on respiratory illness in primary school children in Kuala Lumpur. Int J Epidemiol 1991; 20: 144-150.

Fagbule D, Ekanem EE. Some environmental risk factors for childhood asthma: a case-control study. Ann Trop Paediatr 1994; 14: 15-19. 
91 Kilpelainen M, Terho EO, Helenius H, et al. Home dampness, current allergic diseases, and respiratory infections among young adults. Thorax 2001; 56: 462-467.

92 Quansah R, Jaakkola MS, Hugg TT, et al. Residential dampness and molds and the risk of developing asthma: a systematic review and meta-analysis. PLoS One 2012; 7: e47526.

93 Gotzsche PC, Johansen HK. House dust mite control measures for asthma. Cochrane Database Syst Rev 2008; 2: CD001187.

94 Platts-Mills TA. Allergen avoidance in the treatment of asthma: problems with the meta-analyses. J Allergy Clin Immunol 2008; 122: 694-696.

95 Chipps BE, Zeiger RS, Borish L, et al. Key findings and clinical implications from the epidemiology and natural history of asthma: outcomes and treatment regimens (TENOR) study. J Allergy Clin Immun 2012; 130: 332-342.

96 Kopel LS, Phipatanakul W, Gaffin JM, et al. Social disadvantage and asthma control in children. Paediatr Respir Rev 2014; 15: 256-262. 